\title{
Multiphysics Study of Forced Convection Conjugate Heat Transfer (CHT) Problem
}

\section{A Leyli', H Khawaja1*, M Moatamedi ${ }^{2,3}$ and B Alzahabi²}

1. UiT-The Arctic University of Norway

2. Al Ghurair University, UAE

3. Oslo Metropolitan University, Norway

\begin{abstract}
This paper presents a problem undergoing conjugate heat transfer (CHT). Conjugate heat transfer problems are common domestic heating/cooling, industrial heat exchangers, cooling of electronics (e.g. PC fans). It is to be noted that in conjugate heat transfer problems, the convection part of the heat transfer is dominated.

In the given study, a hypothetical case is built where a heat source (a burning candle) is placed under a thin aluminum sheet. The aluminum sheet is exposed to wind velocity using a fan (velocity of $\sim 1.75 \mathrm{~m} / \mathrm{s}$ ). The aluminum sheet is coated with acrylic paint to increase the infrared emissivity of the surface. FLIRß T1030sc camera is used to visualize the developed infrared signature. Precautions are taken to ensure the correctness of results.

The given problem is simulated using ANSYS ${ }$ Multiphysics, where fluid mechanics equations; continuity, momentum and energy are coupled with the heat equation. This Multiphysics problem is solved using a finite volume method. Mesh sensitivity analysis is performed to ensure the correctness of results.
\end{abstract}

The results from infrared thermography and the Multiphysics model are compared and found to be in reasonable accuracy.

\section{INTRODUCTION}

Heat transfer has three mechanisms including thermal conduction in solids, thermal convection in fluids and thermal radiation by electromagnetic waves. In most of the heat transfer cases, different mechanisms of heat transfer are involved. Heat transfer in solids can be described by Fourier's law as shown in Equation (1). The conductive heat flux, $q\left(\mathrm{~W} / \mathrm{m}^{2}\right)$, has a direct relation with the gradient of $T$ temperature $(\mathrm{K})$ and thermal conductivity coefficient $k(\mathrm{~W} /(\mathrm{m} . \mathrm{K}))[1,2]$.

$$
q=-k \nabla T
$$

When the temperature is time-independent, the temperature field in a constant solid can be described as Equation (2).

$$
\rho c \frac{\partial T}{\partial t}=Q+\frac{\partial}{\partial x}\left(k \frac{\partial T}{\partial x}\right)
$$


Where $\rho\left(\mathrm{kg} / \mathrm{m}^{3}\right)$ is density, $c(\mathrm{~J} /(\mathrm{kg} . \mathrm{K}))$ is heat capacity at constant pressure, $Q\left(\mathrm{~W} / \mathrm{m}^{3}\right)$ is the volumetric energy generation term, $T(\mathrm{~K})$ is temperature field and $t(\mathrm{~s})$ is time. Equation (2) can be written in three spatial dimensions as shown in Equation (3).

$$
\frac{\partial T}{\partial t}=\alpha\left(\frac{\partial^{2} T}{\partial x^{2}}+\frac{\partial^{2} T}{\partial y^{2}}+\frac{\partial^{2} T}{\partial z^{2}}\right)+\frac{Q}{\rho c}
$$

Where $\alpha=\frac{k}{\rho c}\left(\mathrm{~m}^{3} / \mathrm{s}\right)$ and $x, y$ and $z$ refer to cartesian coordinates.

In natural convection, the flow is driven by buoyancy effects. Based on the expected performance the natural convection can be positive or negative. The Rayleigh number, $R a$, characterizes the natural convection flow regime as shown in Equation (4),

$$
R a=\frac{\rho^{2} g \alpha c}{\mu k} \Delta T L^{3}
$$

Where $L(\mathrm{~m})$ is common cavity size, $g\left(\mathrm{~m} / \mathrm{s}^{2}\right)$ is gravity acceleration, $\mu(\mathrm{kg} /(\mathrm{m} . \mathrm{s}))$ is dynamic viscosity of the fluid and $\Delta T(\mathrm{~K})$ is the temperature difference in solids around the fluid.

The Grashof number indicates the ratio of buoyant to viscous forces and can be calculated by Equation (5).

$$
G_{r}=\frac{\rho^{2} g \alpha}{\mu^{2}} \Delta T L^{3}
$$

For Rayleigh numbers bigger than $10^{3}$ heat transfer by convection is dominant and for the smaller ones, the convection can be neglected. When viscous force is larger than buoyancy force the flow is turbulent, otherwise, it is laminar. The transition area between these regimes happens when the Grashof number is $10^{9}[1]$.

In forced convection, the flow is driven by an external force such as wind, fan pumps, etc. In this case, the flow regime is indicated by Reynolds number $R e=\frac{\rho U L}{\mu}$. Where $U(\mathrm{~m} / \mathrm{s})$ is the velocity of the object and $L(\mathrm{~m})$ is the linear characteristic dimension. The Reynolds number $R e$ is the ratio indication of inertial to viscous forces. Very high Reynolds number leads to the turbulent regime and low Reynolds number expresses laminar flow [1].

CHT analysis method has been developed over the years as the most practical way to study heat transfer [3]. In this method, the combined effects of the conduction heat transfer in the solid and convection heat transfer in the fluid are considered together. For example, heat transfer in electronic circuits, space vehicles, nuclear reactors, turbine blade heating or cooling to solar panels $[3,4]$.

Heat flux and heat transfer coefficient of the surfaces having heat transfer with the environment are the most important parameters needed for CHT analysis. To calculate the heat transfer coefficient, a combination of fluid and solid field boundary condition is required. This condition is complex since the wall and freestream parameters change with time. Thus, to solve this problem, various simplified assumptions as in isothermal wall boundary 
condition should be implemented which in practical cases and can lead to inaccuracy of the results. For obtaining the close heat transfer coefficient from numerical analysis and experiments, studying the conjugate heat transfer, which is, the boundary condition at the solid-fluid interface is necessary.

CHT analysis involves several differential equations $[3,5,6]$. An example, where heat transfer in the fluid is governed by energy, continuity, momentum equations is a solid surface with heat conduction from inside and a fluid flow on the external surface as presented in Figure 1. Figure 1 is an example of forced convection over a solid surface where heat transfer in solid and fluid is governed by Fourier's law, energy, momentum and continuity equations as shown in Equations (6-9).

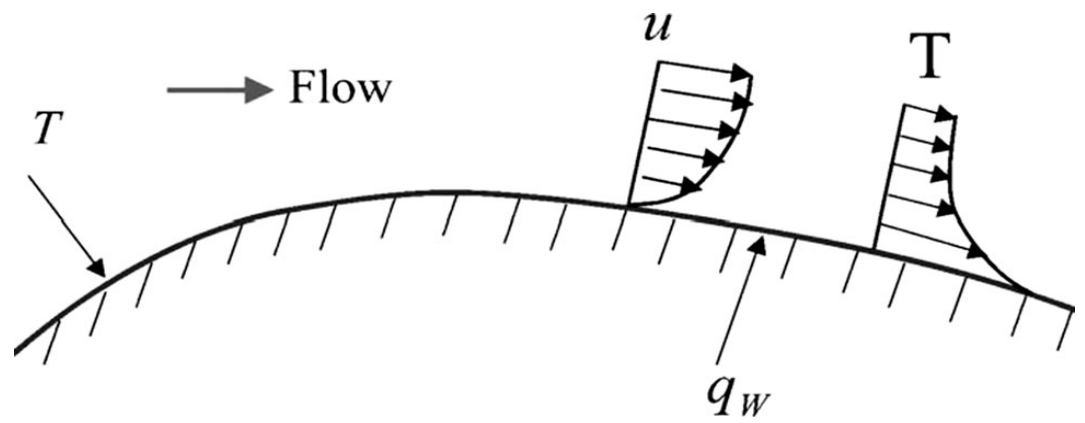

Figure 1 - Illustration of conjugate heat transfer [3]

$$
\begin{gathered}
\frac{\partial u}{\partial x}+\frac{\partial v}{\partial y}=0 \\
\frac{\partial u}{\partial t}+u \frac{\partial u}{\partial x}+v \frac{\partial u}{\partial y}=-\frac{1}{\rho} \frac{d p}{d x}+g \beta\left(T-T_{\infty}\right)+v \frac{\partial^{2} u}{\partial y^{2}} \\
\frac{\partial T}{\partial t}+u \frac{\partial T}{\partial x}+v \frac{\partial T}{\partial y}=\alpha \frac{\partial^{2} T}{\partial y^{2}}+\frac{v}{c}\left(\frac{\partial u}{\partial y}\right)^{2} \\
\rho_{s} c_{s} \frac{\partial T_{s}}{\partial t}=\lambda_{s}\left(\frac{\partial^{2} T_{s}}{\partial x^{2}}+\frac{\partial^{2} T_{s}}{\partial y^{2}}\right)+q_{w}
\end{gathered}
$$

The conjugate and boundary conditions are defined by Equations $(9,10)$, while the initial conditions differ for each problem:

$$
\begin{aligned}
& y=0, \quad u=v=0, \quad y \rightarrow \infty, \quad u \rightarrow U, \quad T \rightarrow T_{\infty} \\
& y=0, \quad T_{s}=T_{w}, \quad \lambda_{s}\left(\frac{\partial T_{s}}{\partial y}\right)_{y=0}=\lambda\left(\frac{\partial T}{\partial y}\right)_{y=0}
\end{aligned}
$$

Where $u$ and $v$ are velocity components in two dimensions, $p(\mathrm{~Pa})$ is pressure, $\beta(1 / \mathrm{K})$ is dimensionless pressure gradient in self-similar solutions and turbulent equilibrium boundary 
layer or volumetric thermal expansion coefficients, $\lambda(\mathrm{W} /(\mathrm{m} . \mathrm{k}))$ is thermal conductivity, $s$ subscript refers to solid, $w$ refers to fluid-solid interface and $\infty$ indicates being far from the solid.

CHT problems can be solved either by numerical models or analytical methods. Analytical solutions for convection and conduction problems individually are easier, while, CHT problems are much more challenging to solve. [7]. As an example, choosing one-dimensional heat equation leads to a simple analytical solution in the solid fluid interface, while choosing multi-dimensional equations entails a thorough meshing of the solid domain and finite element or difference method solving. For conjugating the solid and fluid domain there are mainly two different methods. The first method is the approach when all the equations in fluid and solid domain are solved together. The second method is the iterative approach where solid and fluid domains are solved separately and only the solutions are combined at the interface [7].

The quick progress of computational fluid dynamics and its ease to get accurate results by solving all the governing equations with few or even no assumptions have made CHT analysis more realistic [3].

CHT problems are common in several engineering equipment such as heat exchangers, building assessment and material processing [8-11]. It is possible to study CHT problems with infrared thermography.

Infrared thermography technique is commonly used today in many engineering applications [12]. It uses electromagnetic radiation emitted by objects. False colors can be used to visualize the radiations [11]. Electromagnetic (EM) radiation is a flow of waves having energy and moving at the speed of light. The electromagnetic spectrum can be expressed by wavelength or frequency. EM spectrum consists of all EM radiation. EM spectrum includes radio waves, microwaves, infrared, visible light, ultraviolet, X-ray and gamma-ray. Waves with the shorter wavelength have higher energy and vice versa [13].

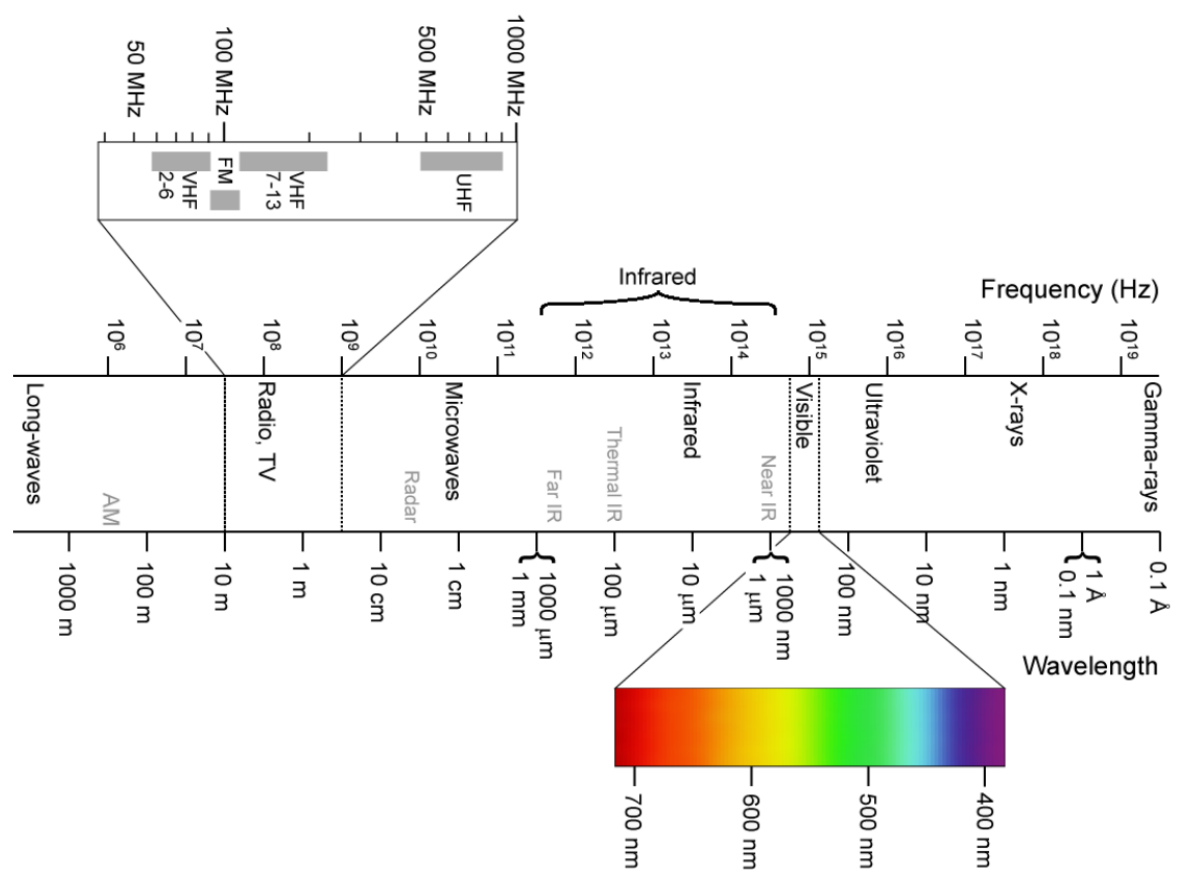

Figure 2 - EM Spectrum [14] 
Figure 2 shows the whole EM spectrum and each wave type frequency and wavelength. Infrared (IR) refers to the wavelengths from $700 \mathrm{~nm}$ to $0.001 \mathrm{~m}$. The infrared light has a photon energy of 1.24 to $1.7 \mathrm{meV}$ [14]. IR spectrum can be divided into four sub-bands; near-infrared (NIR), shortwave infrared (SWIR), middle infrared (MWIR), and long infrared [15, 16]. Any object above -273 degrees Celsius (absolute zero) have thermal radiation and its due to the atomic motion of the particles of each object. The objects thermal radiation around $273 \mathrm{~K}$ is in the range of infrared [13, 17]. Stefan-Boltzmann defines the thermal energy emission according to surface temperature based on Equation (12) [18].

$$
q=\varepsilon \sigma A\left(T_{s}^{4}-T_{\infty}^{4}\right)
$$

Where $q$ is heat transfer per unit time (W), $\varepsilon$ (dimensionless) is emissivity compared to black body, $\sigma$ is Stefan-Boltzmann constant $\left(\mathrm{W} / \mathrm{m}^{2} . \mathrm{K}^{4}\right), A$ is the emission surface area $\left(\mathrm{m}^{2}\right)$, $T_{S}$ is surface temperature $(\mathrm{K})$ and $T_{\infty}$ is the ambient temperature $(\mathrm{K})$.

The surface temperature has a significant influence on energy emission as thermal radiation [19]. Acrylic paint emissivity is reported approximately about 0.94 [20], which may change with emission wavelength and temperature. Infrared detection devices including IR cameras capture IR wavelengths and average the results to make the IR signature [21]. An example of IR image is shown in Figure 3.

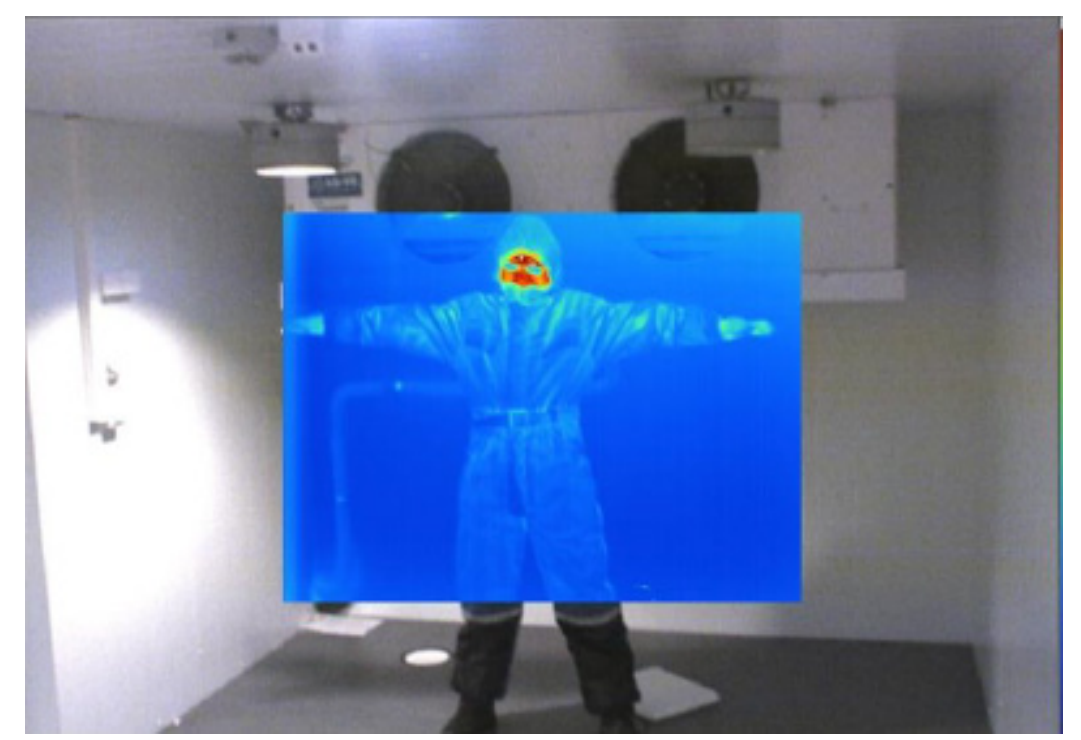

Figure 3 - Example of infrared imaging [22]

In the presented work IR thermography is used to study a CHT problem. The nature of the problem involves heat transfer in solid and forced convection which includes conduction and convection and coupling of heat transfer, energy, continuity and momentum equations. The case study is analyzed by IR thermography and simulated in ANSYS ${ }^{\circledR}$ fluent using finite volume method [23]. 


\section{METHODOLOGY}

The objective of this study is to demonstrate that a CHT problem can be studied by IR thermography. In this paper, an experimental model is built. The hypothetical model undergoes conjugate heat transfer and is analyzed by IR thermography and simulated by ANSYS ${ }^{\circledR}$ Multiphysics. In this section, the methodology to carry out the experiment and simulation is explained.

\subsection{EXPERIMENTAL METHOD}

An experimental model is used to analyze the heat transfer case study. In the experimental model, a burning candle is placed under a thin aluminum sheet. The aluminum sheet is a square $28 \times 28 \mathrm{~cm}$ and is exposed to a wind velocity of $\sim 1.75 \mathrm{~m} / \mathrm{s}$ generated by the fan. The fan wind velocity is controlled via a voltage regulator. The candle is put in a small square wooden box $(6 \times 6 \mathrm{~cm})$ for leading the heat to the sheet more accurately. The aluminum sheet is coated with acrylic paint to enhance the infrared emissivity of the surface. The equipment and the experimental setup are shown in Figure 4.

Visualizing the IR signature is conducted by the high performance, full color and battery powered FLIR ${ }^{\circledR}$ T1030sc IR camera. Some of the IR camera specifications are shown in table 1.

Table 1 - IR camera specifications [24]

\begin{tabular}{ll}
\hline IR Sensor & $1024 \times 768$ pixels \\
Thermal Sensitivity & $<20 \mathrm{mK}$ at $+30^{\circ} \mathrm{C}\left(+86^{\circ} \mathrm{F}\right)$ \\
Object temp. range & $+100^{\circ} \mathrm{C}$ to $+650^{\circ} \mathrm{C}\left(+212^{\circ} \mathrm{F}\right.$ to $\left.+1202^{\circ} \mathrm{F}\right)-40^{\circ} \mathrm{C}$ to $+150^{\circ} \mathrm{C}$ \\
& $\left(-40^{\circ} \mathrm{F}\right.$ to $\left.+302^{\circ} \mathrm{F}\right)+300^{\circ} \mathrm{C}$ to $+2000^{\circ} \mathrm{C}\left(+572^{\circ} \mathrm{F}\right.$ to $\left.+3632^{\circ} \mathrm{F}\right)$ \\
& $\pm 1{ }^{\circ} \mathrm{C}\left( \pm 1.8^{\circ} \mathrm{F}\right)$ or $\pm 1 \%$ at $25^{\circ} \mathrm{C}$ for temperatures between $5^{\circ} \mathrm{C}$ to \\
& $150^{\circ} \mathrm{C} \pm 2^{\circ} \mathrm{C}\left( \pm 3.6^{\circ} \mathrm{F}\right)$ or $\pm 2 \%$ of reading at $25^{\circ} \mathrm{C}$ for \\
& temperatures up to $1200^{\circ} \mathrm{C}$ \\
Emissivity Correction & Variable from 0.01 to 1.0 or selected from materials list \\
\hline
\end{tabular}

For data recording and thermal analysis FLIR ${ }^{\circledR}$ ResearchIR Max software is used. The software interface is shown in Figure 5.

\subsection{SIMULATION METHOD}

The geometry sketched for simulation by Design modeler in ANSYS ${ }^{\circledR}$. The whole model is considered as a box and divided into two parts by symmetry to reduce the calculations in the simulation. The half of geometry is divided into six smaller boxes to make a mapped mesh and apply the boundary conditions. The geometry's drawing with dimensions in millimeters is shown in Figure 6.

Simulating the model was performed by, ANSYS ${ }^{\circledR}$ Fluent. For the viscosity model, the laminar flow was chosen due to the low Reynolds number $(R e \sim 14400)$ which is lower than the critical Reynolds number for external flow $\sim 500000$. The simulation was set to a pressurebased, SIMPLE algorithm. In the simulation run the gradient is least-square cell-based, the pressure is of second order and momentum and energy equations are solved with second-order upwind method. The solution is achieved by double precision and parallel processing. 
The mesh is generated by dividing the whole box to six smaller blocks to make a mapped and structured mesh. The mesh is generated by edge sizing on each block shown in Figure 7. The mesh becomes smaller towards the case study. The correctness of results was ensured by mesh sensitivity analysis. The final mesh grid included 413526 nodes and 384000 elements. The final meshing of CAD model parameters is shown in table 1. Figure 8 shows the mesh grid of the geometry.
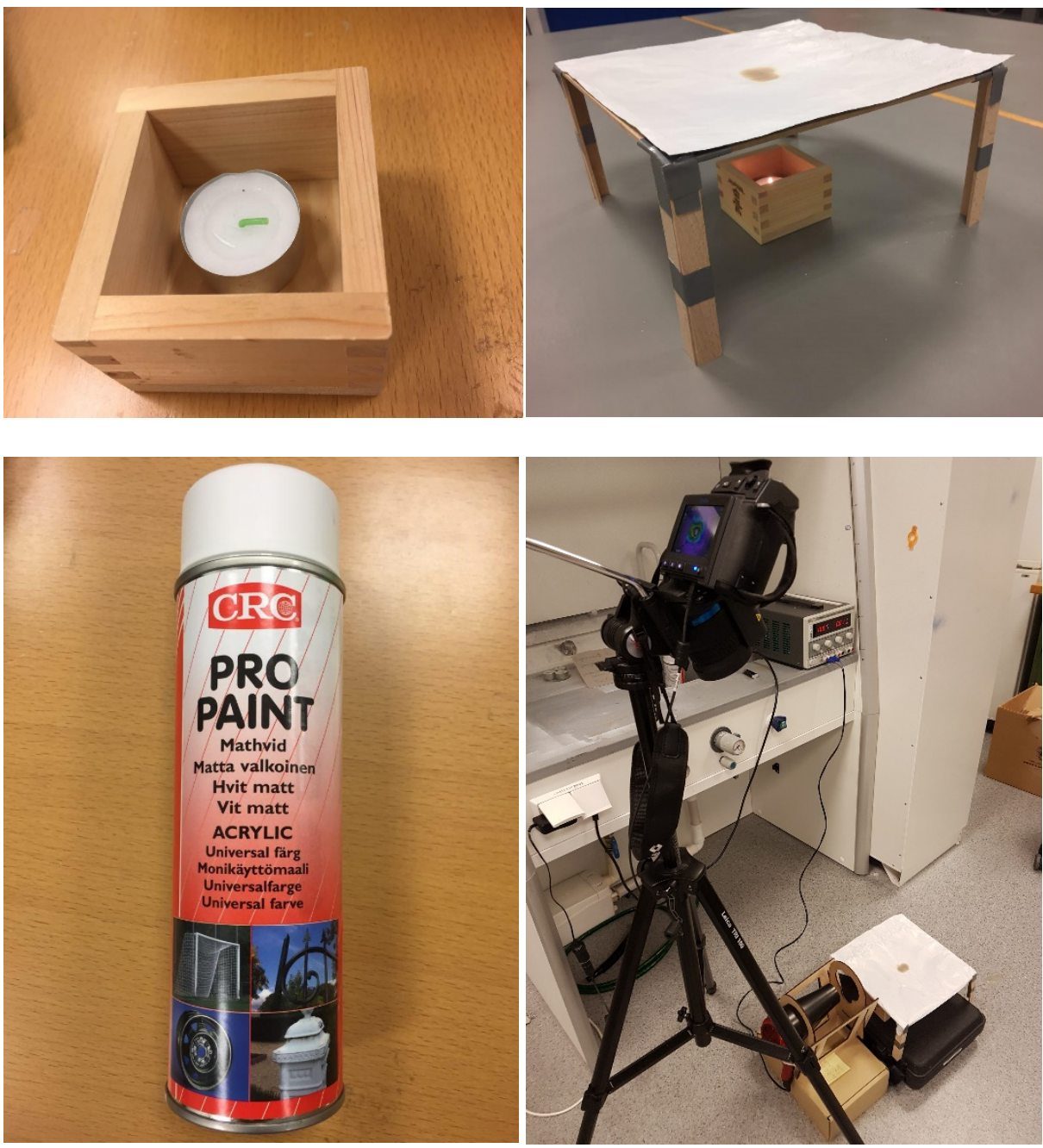

Figure 4 - Experimental equipment and setup 


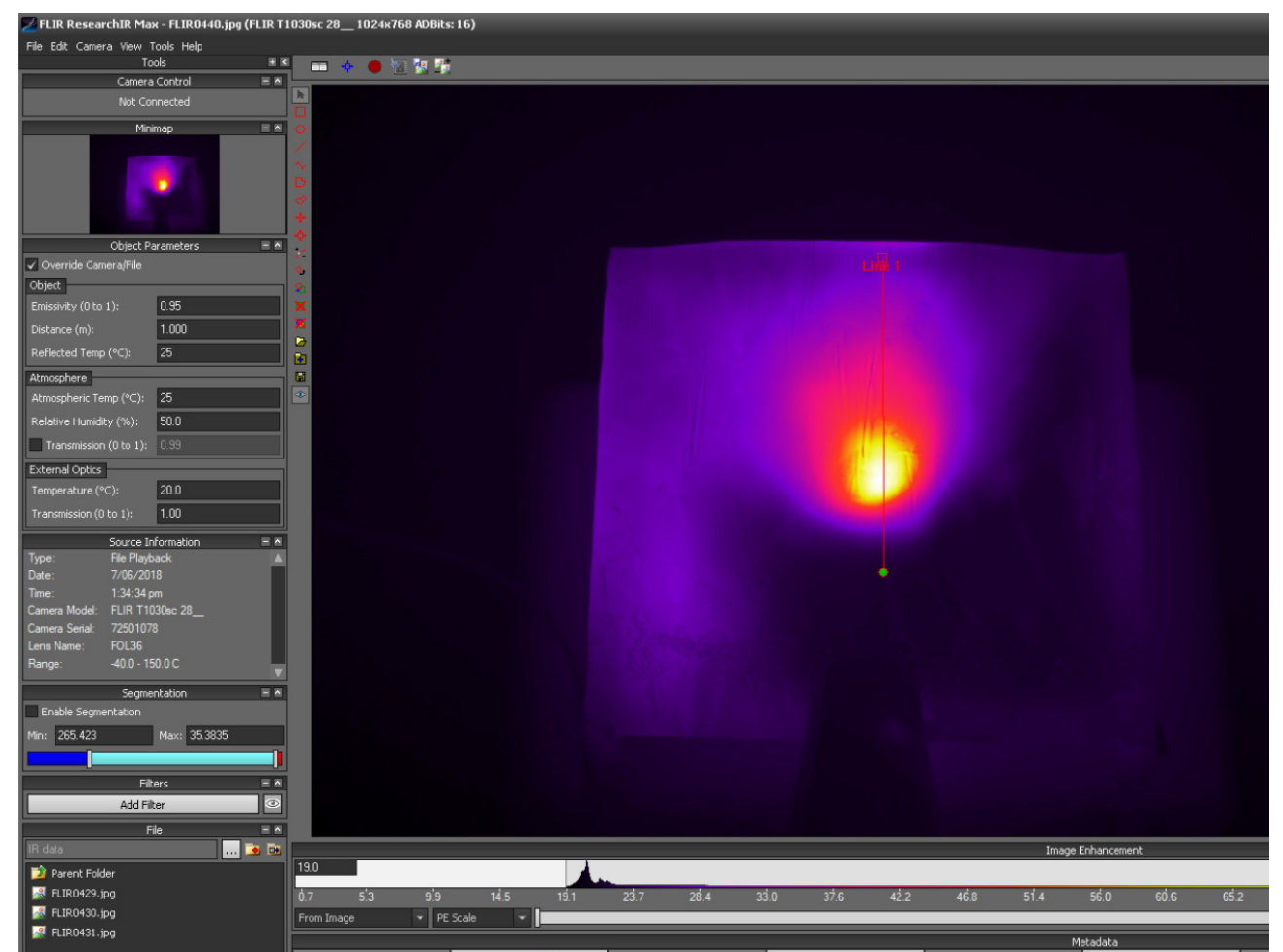

Figure 5 - FLIR® ResearchIR Max software
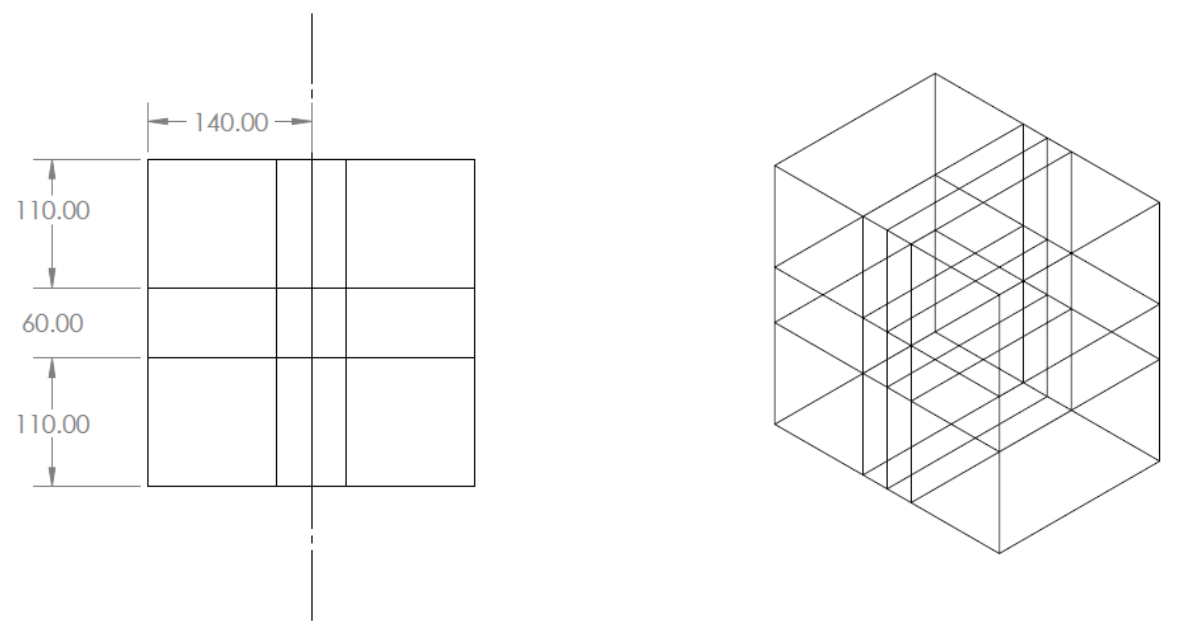

Figure 6 - Simulation model geometry 
Table 2 - CAD model meshing parameters

Max Face Size

Mesh de-featuring

De-feature Size

Capture Curvature

Curvature Min Size

Curvature Normal Angle

Capture Proximity

Smoothing
$3.7148 \mathrm{e}-002 \mathrm{~m}$

Yes

9.2871e-005 m

Yes

$1.8574 \mathrm{e}-004 \mathrm{~m}$

$18^{\circ}$

No

Medium

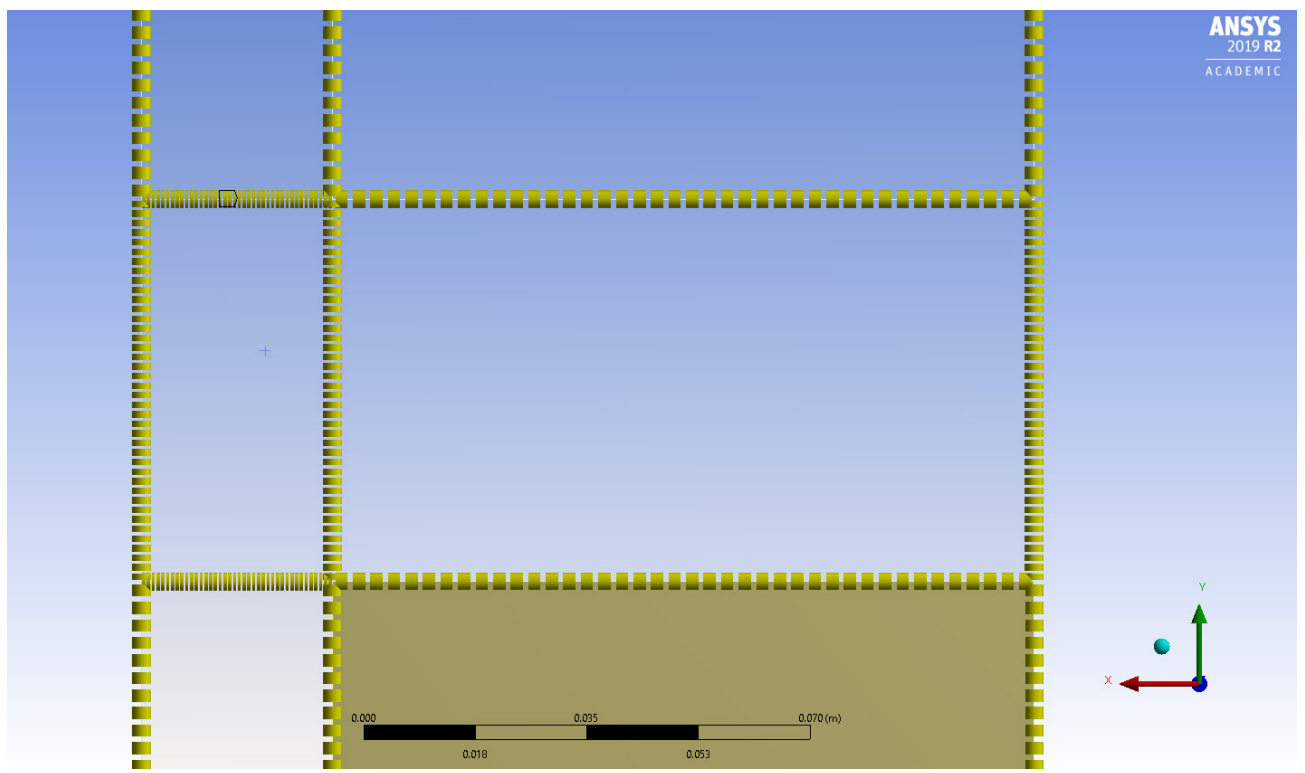

Figure 7 - Mesh edge sizing

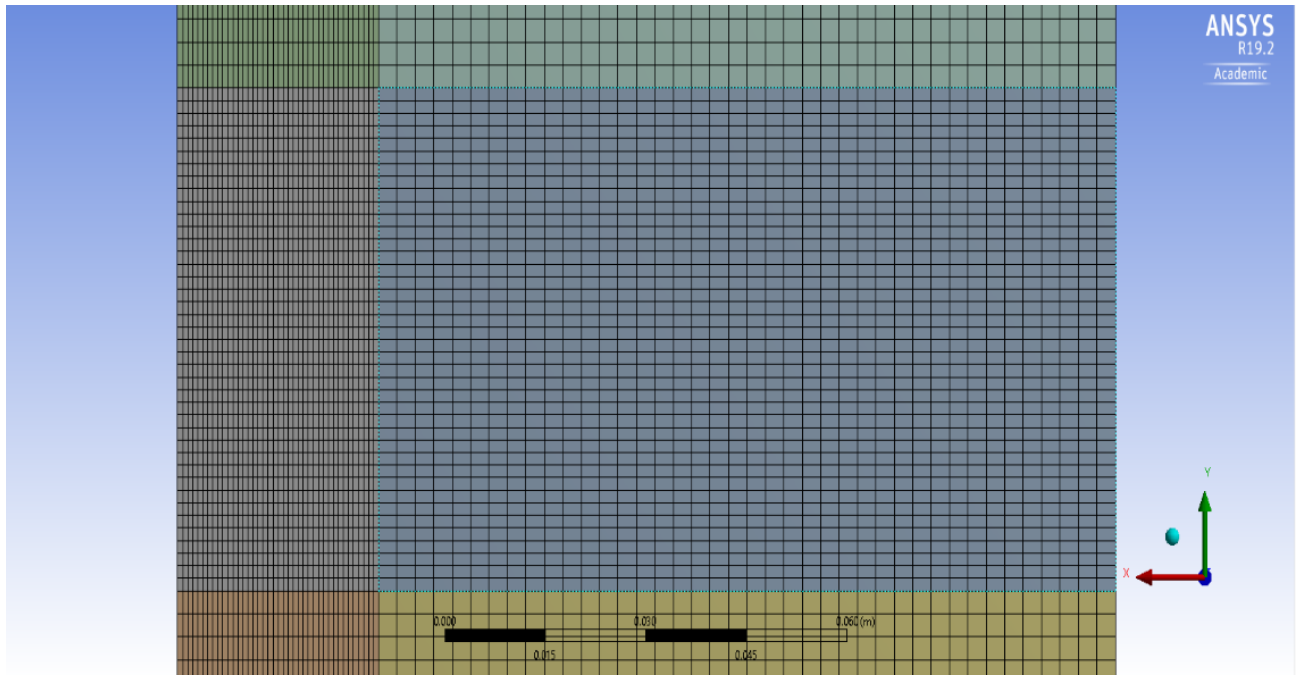

Figure 8 - The mesh grid top view of the simulation 
For the boundary condition, the far-field is the model external walls considered as velocity inlet. The velocity inlet is the fan wind which has $2 \mathrm{~m} / \mathrm{s}$ velocity in $+\mathrm{Y}$ direction and the thermal condition of $298 \mathrm{~K}$ due to the fan being in room temperature. The heater is the surface above the candle flame wooden box and is stationary no-slip wall with a fixed temperature of $390 \mathrm{~K}$. Heater surface is the aluminum sheet excluding the heater. The heater is also considered as a wall with zero velocity on the surface. The rest of the simulation model are considered as wall including symmetry plane. The boundary condition of the surfaces is shown in table 3 .

Table 3 - Boundary condition of model surfaces

\begin{tabular}{ll}
\hline Far-field & Velocity inlet \\
Heater & Wall (Fixed temperature) \\
Heater Surface & Wall \\
Symmetry & Wall \\
Interior block planes & Wall \\
\hline
\end{tabular}

\section{RESULTS AND DISCUSSIONS}

This section discusses the results from the CHT experimental model and CFD simulation. The presented results are focused on showing the accuracy of experimental results collected by IR thermography and Multiphysics modelling by ANSYS ${ }^{\circ}$.

\subsection{EXPERIMENTAL RESULTS}

The results from IR thermography shows how the heat dissipates over the aluminum sheet being exposed to candle flame from underneath. Figure 9 shows the IR thermography signature when the sheet is not exposed to the wind by the fan. From the temperature contour and the generated colors of the IR signature, it can be seen that the highest temperature on the aluminum sheet refers to the point exactly above the candle flame with 144 degrees Celsius and distinguished by white color. The temperature reduces in a circular pattern by getting farther from the flame indicated by different colors. The minimum temperature in this condition is reported $18.8^{\circ} \mathrm{C}$ and it refers to the corners of the sheet shown by the dark purple color.

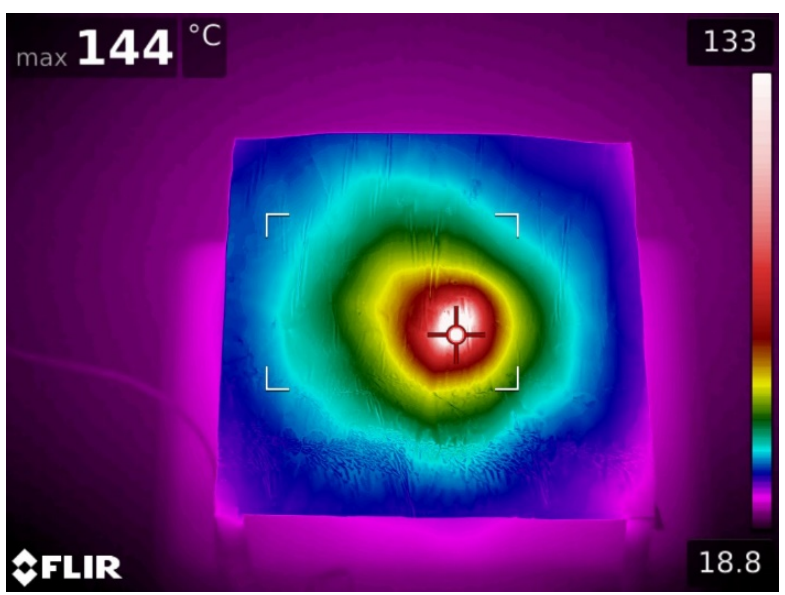

Figure 9 - IR signature without wind 
In Figure 10, A to D, the IR signature of the experimental model when exposed to a fan wind velocity of $\sim 1.75 \mathrm{~m} / \mathrm{s}$ in various times can be seen. By looking at the IR images it can be said that the wind makes the heat flow over the aluminum sheet and reduces gradually in the wind direction by getting farther from the heat source (candle flame). The temperature contour in Figure 10 (A) shows the maximum temperature of $87.6{ }^{\circ} \mathrm{C}$ which is $56.4{ }^{\circ} \mathrm{C}$ less than no wind condition therefore, the wind also reduces the heat generation on the sheet. The images A to $\mathrm{D}$ shows how the heat dissipates over the sheet over the time and maximum temperatures reported are $87.6,83.5,39.6$ and $38.2{ }^{\circ} \mathrm{C}$. The temperature reduces as the sheet is exposed to wind for more time. Figure 10 (D) is referred to the time when the heat generation over the sheet is stabilized after a while. The heat is flown by the fan wind and the different temperatures are indicated by various colors. The maximum and minimum temperatures reported in this case are 38.2 and 20.2 degrees Celsius respectively.

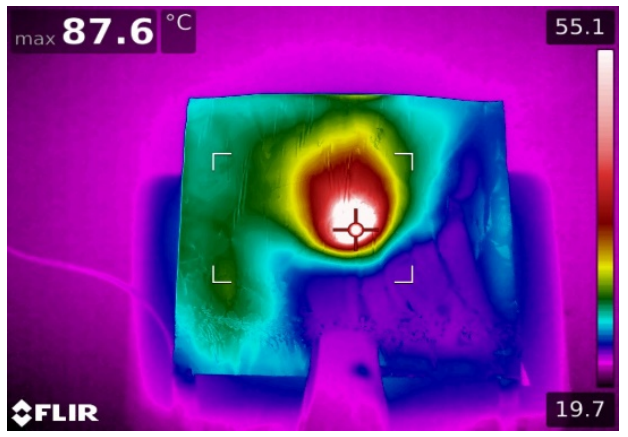

A)

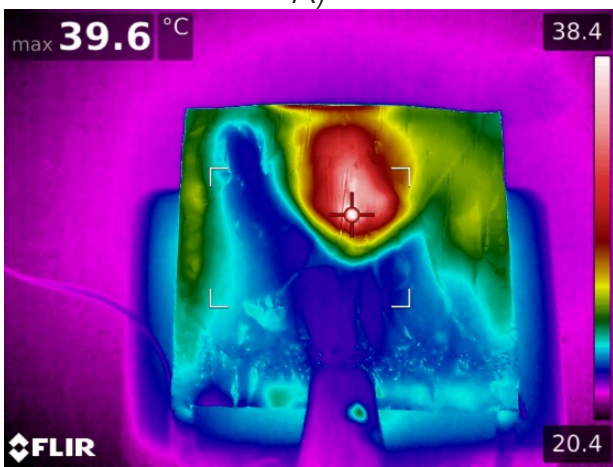

C)

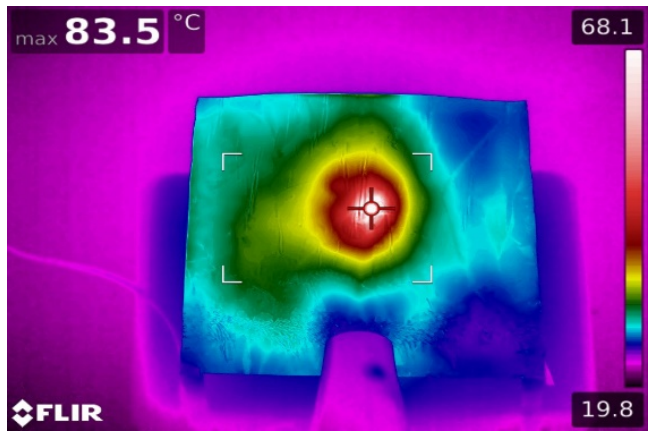

B)

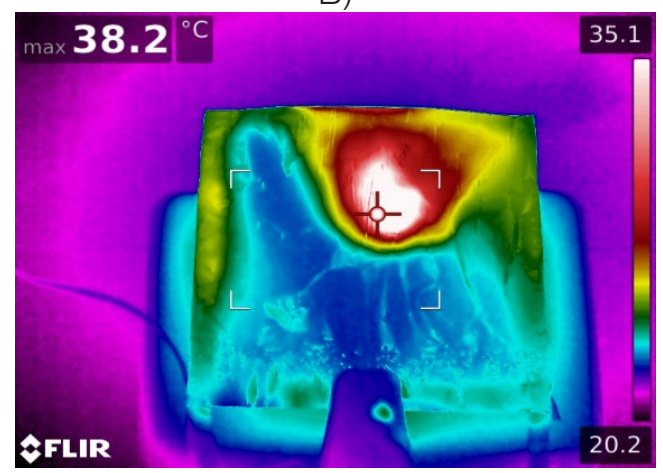

D)

Figure 10 - IR signature of experimental model exposed to wind

\subsection{SIMULATION RESULTS}

Figure 11 shows the visualization of simulation data from Multiphysics modelling, where the heater surface is exposed to an external laminar airflow of $2 \mathrm{~m} / \mathrm{s}$ and $298 \mathrm{~K}$ and a fixed temperature surface of the heater by $390 \mathrm{~K}$. A $10 \mathrm{~cm}$ line is drawn from the end of the heater to almost end of the heater surface to generate the temperature contour over it. The results show that the temperature reduces over the surface in the airflow direction and is indicated by various colors. The maximum temperature is the heater temperature starting from $90{ }^{\circ} \mathrm{C}$ (red) and decreasing slowly to around $40{ }^{\circ} \mathrm{C}$ distinguished by aqua blue color. 


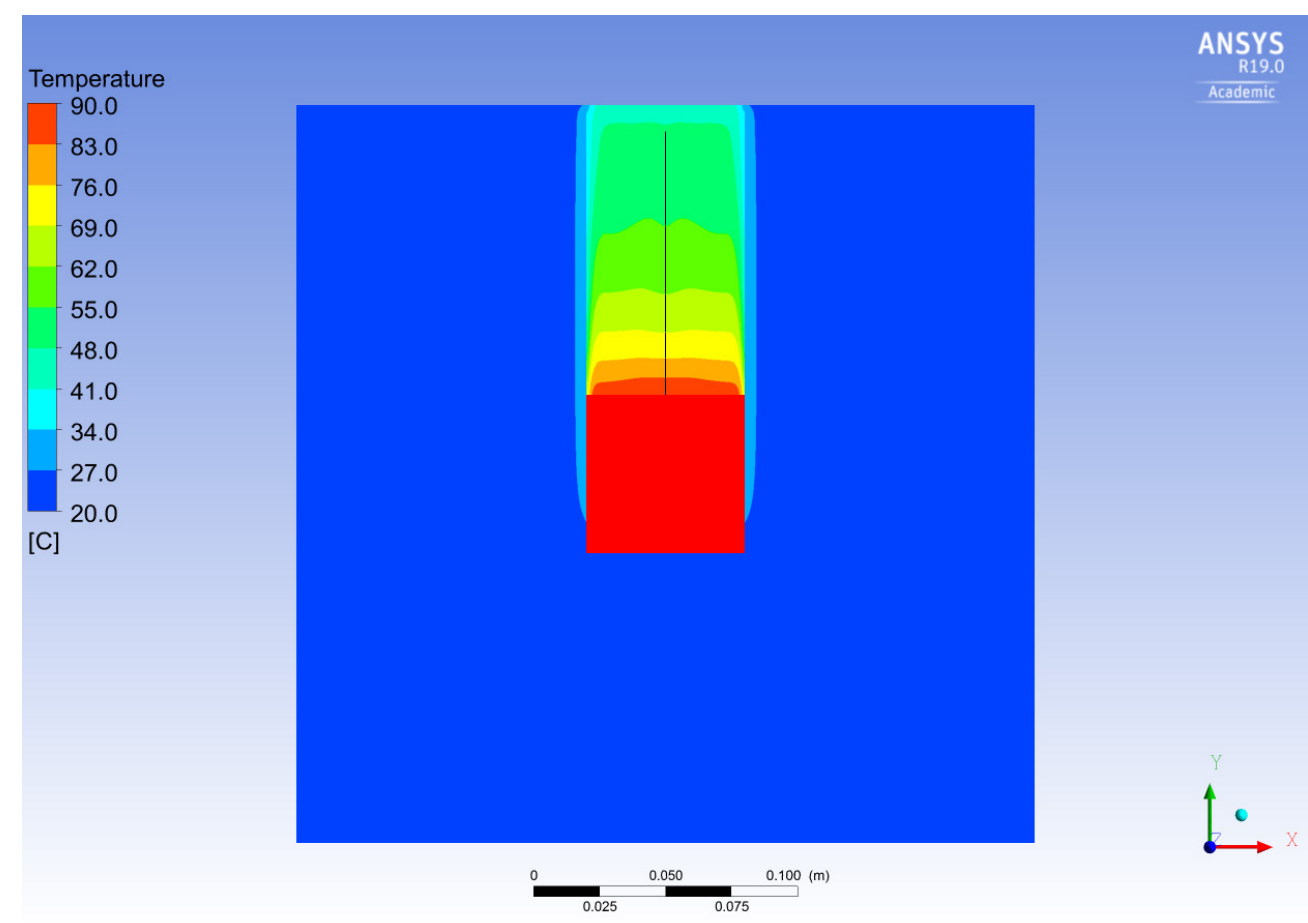

Figure 11 - Simulation results in heater surface

\subsection{COMPARISON OF RESULTS}

Figure 12 shows the plots for heat dissipation over the case study in terms of temperature and space. The horizontal axis is the $10 \mathrm{~cm}$ space dimension and the vertical axis is the temperature in degrees Celsius. The graphs are plotted by experimental and CFD results from the IR thermography signature and ANSYS ${ }^{\circledR}$ simulation.

A general downward trend in both graphs shows the temperature decrease over the distance which is due to heat loss. The maximum temperature refers to $0 \mathrm{~cm}$ distance and is $91.79^{\circ}$ and $89.45^{\circ}$ in experiments and simulation respectively with $2.34 \%$ error. The minimum temperature reported by results is $45.19^{\circ}$ for IR thermography and $48.89^{\circ}$ in simulation having $3.7 \%$ difference. The least error refers to $5.45 \mathrm{~cm}$ distance by $0.02 \%$ and having the temperatures of $57.02^{\circ}$ and $57^{\circ}$ and the maximum error is in $1.81 \mathrm{~cm}$ distance by $6.78 \%$ and temperatures of $79.36^{\circ}$ and $72.58^{\circ}$ in experiments and simulation in turn. The average error of the results is 3.46 percent therefore, it can be said that the results of both methods match reasonably and at some distances very close to each other. 


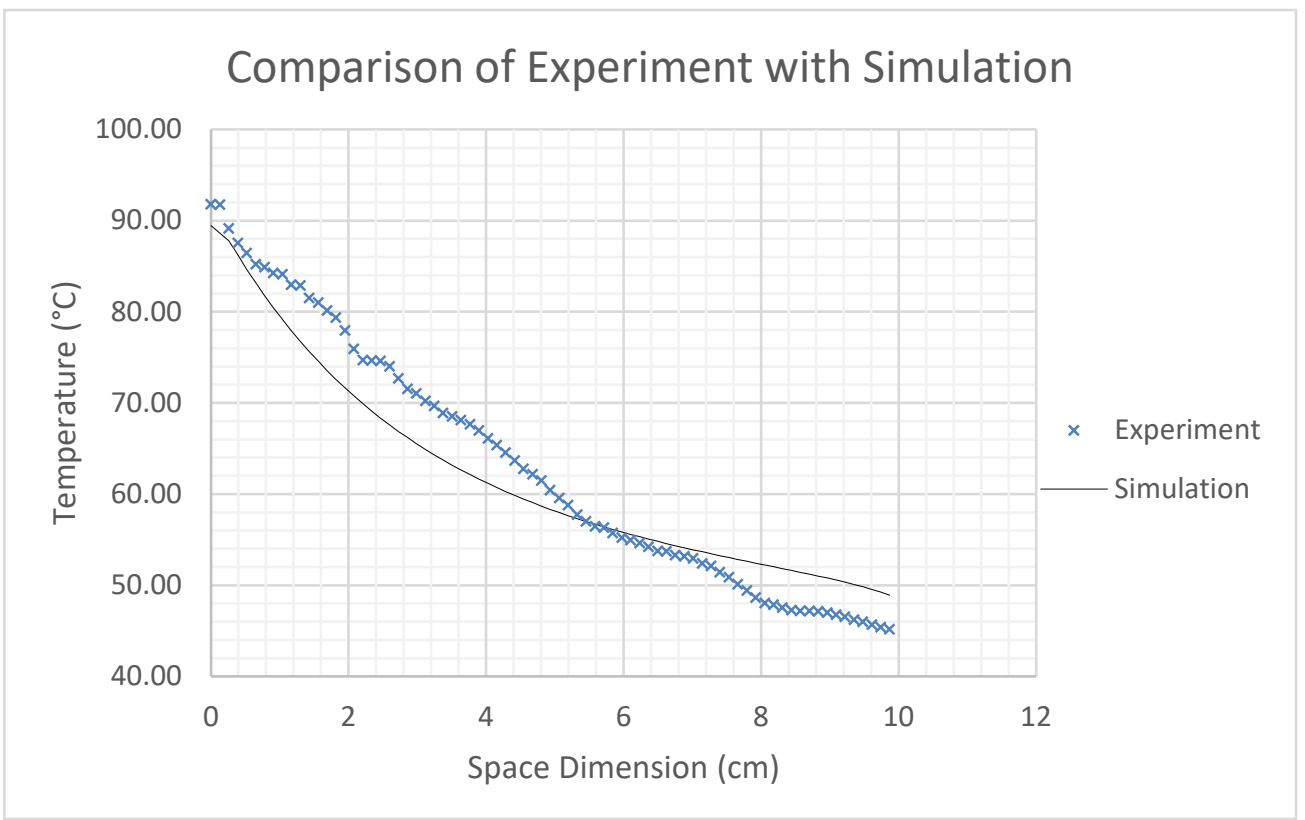

Figure 12 - Comparison of experimental and simulation results

\section{CONCLUSION}

The following conclusion can be drawn from the presented study:

- A hypothetical model of a conjugate heat transfer problem is built. The problem is analyzed by IR thermography camera and simulated by ANSYS ${ }^{\circledR}$.

- The flow characteristics, mesh grid generation and simulation method were found to have a reasonable accuracy for the case study.

- The experimental results from IR thermography and CFD simulation were compared and found to be in fairly good agreement.

- IR thermography can be considered as a useful method for analyzing conjugate heat transfer problems.

\section{REFERENCES}

[1] Dorfman, A.S., Conjugate problems in convective heat transfer. 2009: CRC Press.

[2] Rashid, T., H.A. Khawaja, and K. Edvardsen, Determination of thermal properties of fresh water and sea water ice using multiphysics analysis. Rashid, T.(2019). Monitoring of Marine Ice and its Thickness for Ship Anti-/De-icing-Experimental and Analytical Study using Infrared Thermography. (Doctoral thesis).

[3] John, B., P. Senthilkumar, and S. Sadasivan, Applied and Theoretical Aspects of Conjugate Heat Transfer Analysis: A Review. Archives of Computational Methods in Engineering, 2018: p. 1-15.

[4] Pelletier, D., L. Ignat, and F. Ilinca. An adaptive finite element method for conjugate heat transfer. in 33rd Aerospace Sciences Meeting and Exhibit. 1995. 
[5] Khawaja, H. and M. Moatamedi, Semi-Implicit Method for Pressure-Linked Equations (SIMPLE) - solution in MATLAB®. The International Journal of Multiphysics, 2018. 12(4), p. 313-326.

[6] Nordli, A. and H. Khawaja, Comparison of Explicit Method of Solution for CFD Euler Problems using MATLAB ${ }^{\circ}$ and FORTRAN 77. The International Journal of Multiphysics, 2019. 13(2), p. 203-214.

[7] Shah, K. and A. Jain, An iterative, analytical method for solving conjugate heat transfer problems. International Journal of Heat and Mass Transfer, 2015. 90: p. 1232-1240.

[8] Rizk, T.A., C. Kleinstreuer, and M.N. Özisik, Analytic solution to the conjugate heat transfer problem of flow past a heated block. International Journal of Heat and Mass Transfer, 1992. 35(6): p. 1519-1525.

[9] Dimelow, A. Steady and transient Conjugate heat transfer analysis of a turbocharger. in Institution of Mechanical Engineers - 13th International Conference on Turbochargers and Turbocharging 2018. 2018.

[10] Stange, E., et al., Multiphysics Study of Tensile Testing using Infrared thermography. The International Journal of Multiphysics, 2019. 13(2), p. 191-202.

[11] Rashid, T., H.A. Khawaja, and K. Edvardsen, Measuring thickness of marine ice using IR thermography. Cold Regions Science and Technology, 2019. 158: p. 221-229.

[12] Zhong, L., G. Wang, and Y. Xia. Infrared thermography to measure heat transfer of a heated curved thin sheet. in ASME International Mechanical Engineering Congress and Exposition, Proceedings (IMECE). 2018.

[13] UrRehman, S., F. MohsinZakai, and M. Adeel. Inspection on Infrared-Based Image Processing. in 2018 IEEE 21st International Multi-Topic Conference (INMIC). 2018. IEEE.

[14] Khawaja, H., et al., Multiphysics Simulation of Infrared Signature of an Ice Cube. The International Journal of Multiphysics, 2016. 10(3), p. 291-302.

[15] Ahmad, T., et al., Study of the required thermal insulation (IREQ) of clothing using infrared imaging. The International Journal of Multiphysics, 2017. 11(4), p. 413 - 426.

[16] Rashid, T., H.A. Khawaja, and K. Edvardsen, Determination of Thermal Properties of Fresh Water and Sea Water Ice using Multiphysics Analysis. International Journal of Multiphysics, 2016. 10(3), p. 277-291.

[17] Howell, J., R. Siegel, and M.P. Mengüç, Thermal Radiation Heat Transfer. 2010.

[18] G.F.S., The constant $\sigma$ of the Stefan-Boltzmann law. Journal of the Franklin Institute, 1925. 199(1): p. 64.

[19] Stange, E., et al., Qualitative visualization of the development of stresses through infrared thermography. Vestnik of MSTU. 2019 (accepted)

[20] ThermoWorks. Emissivity Table. 2018; Available from: https://www.thermoworks.com/emissivity_table.

[21] Rogalski, A., Infrared Detectors. Second ed. 2010: CRC Press. 
[22] Ahmad, T., et al., Study of Wind Chill Factor using Infrared Imaging. International Journal of Multiphysics, 2016. 10(3), p.325-341.

[23] Brunner, D., et al., CFD modelling of pressure and shear rate in torsionally vibrating structures using ANSYS CFX and COMSOL Multiphysics. International Journal of Multiphysics, 2018. 12(4).

[24] FLIR ${ }^{2}$, T1030sc IR Camera, FLIR systems Inc. 
230 